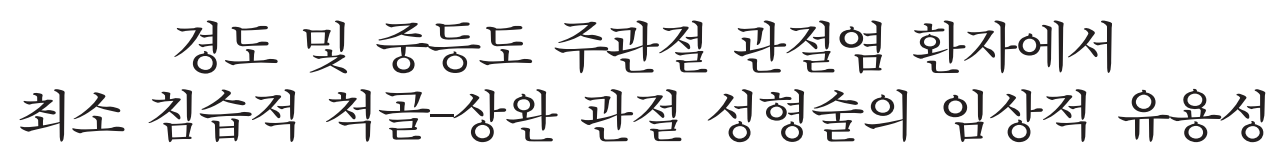

충남대학교 의과대학 정형외과학교실, 동아대학교 의과대학 정형외과학교실*

김보건* · 신현대 · 김경천 · 차수민

\title{
The Clinical Usefulness of the Minimal Invasive Ulno-humeral Arthroplasty in the Patients with Mild to Moderate Elbow Arthritis
}

\author{
Bo-Kun Kim, M.D.*, Hyun-Dae Shin, M.D., Ph.D., Kyung-Cheon Kim, M.D., Ph.D., Soo-Min Cha, M.D. \\ Department of Orthopedic Surgery, Chungnam National University College of Medicine, Daejeon, Korea \\ Department of Orthopedic Surgery, Dong-A University College of Medicine, Busan, Korea*
}

\begin{abstract}
Purpose: To evaluate of the clinical usefulness of minimal invasive ulnohumeral arthroplasty in patients with mild to moderate elbow arthritis.

Materials and Methods: From January 2000 to December 2008, twenty-nine patients with mild to moderate elbow arthritis underwent minimal invasive ulnohumeral arthroplasty. Among these patients, we reviewed the cases of 24 patients for whom we had follow-up data for at least 1 year. There were 20 males and 4 females with a mean age of 53 years (range: 31 69). We excluded patients with preoperative ulnar neuropathy symptoms and investigated the mean operation time, the joint range of motion, the time required until the start of joint exercise, and the Mayo elbow performance score (MEPS).

Results: Passive and active joint exercises were started in an average of 1.8 days (range: 1 4) after surgery; the mean operation time was 38 minutes (range: 25 55). The elbow joint range of motion was 25-104 degrees (extension 0 70, flexion 80 130) preoperatively and was improved 40 degrees on average to 14-133 degrees (extension 0 45, flexion 90 150) after a year of follow up. The average time required until the start of joint exercise was 1.6 days (range: 1 5). MEPS were excellent in 9 cases and good in 5 cases after a year of follow up. Although there was 1 case of delayed wound healing and 7 cases of postoperative edema, they improved spontaneously.

Conclusion: For patients with mild to moderate elbow arthritis, minimal invasive ulnohumeral arthroplasty is a clinically useful surgery since its operation time is short, early joint exercise is possible, and pain is mild.
\end{abstract}

Key Words: Elbow, Arthritis, Minimal invasive ulno-humeral arthroplasty

\footnotetext{
※통신저자: 신 현 대

대전광역시 중구 대사동 640 번지

충남대학교병원 정형외과
}

Tel: 042) 280-7349, Fax:042) 252-7098, E-mail: hyunsd@cnu.ac.kr

접수일: 2011년 2월 7일, 1차 심사완료일: 2011년 5월 3일, 2차 심사완료일: 2011년 5월 27일, 게재 확정일: 2011년 5월 31일

* 이 논문은 동아대학교 교내연구비 지원에 의하여 연구됨. 


\section{서 론}

주관절의 일차성 퇴행성 관절염은 보통 중년에서 호 발하는 질환이며 경증 및 중등도의 관절염 환자에서 굴 곡 구축, 기계적 충돌 그리고 통증이 흔한 임상적 양상 으로 일상 생활 및 직업 활동의 제한을 초래한다. ${ }^{1)}$ 단 순 방사선 촬영상에서는 주두와 구상돌기에서 골극과 골의 과성장, 유리체 등을 관찰할 수 있다. ${ }^{2)}$ 1978년 Kashiwagi의 골 천공술 (Outerbridge-Kashiwagi procedure, OK 술식)이 발표된 이후, 주두 돌출부의 제거, 관상톱 (trephine)을 이용한 상완골의 천공, 그 리고 구상돌기 돌출부의 제거에 우수한 임상결과가 발 표되고 있다." 1992년 Morrey는 '변형된 OK 술식 (modified OK procedure)' 을 소개하며 삼두근을 젖 히고 주두와를 노출시키는 방법을 보고하였다. ${ }^{4.5)}$ 그러 나 이러한 수술 방법들은 비교적 피부 절개가 크고 수 술 시간이 길어 수술 후 환자 관리에서 많은 주의가 요 구된다. 이에 저자들은 척골 신경병증이 없는 경도 및 중등도의 주관절 관절염 환자에서, 피부 절개와 박리를 최소화한 '최소 침습적 척골 상완 관절 성형술 (mini- mal invasive ulnohumeral arthroplasty)' 을 시행 하고 그 임상 결과를 술식과 함께 보고하고자 한다.

\section{연구 대상 및 방법}

2000년 1월에서 2008년 12월까지 주관절 동통과 관 절 운동 장애로 내원한 환자 중 골절의 합병증이나 류 마티스 등의 전신 염증성 질환 등으로 인한 경우를 제 외하였으며, 최대 굴곡 및 신전자세에서 통증 및 운동 제한을 호소는 경도 및 중등도의 일차성 주관절염 환자 들 중 본원에서 최소 침습적 척골-상완 성형술을 시행 받은 환자 29예 중 1년 이상 추시가 가능하였던 24예 환자를 대상으로 연구하였다. 평균 추시 기간은 22 개월 (12 48개월)이었으며 수술 적응증은 최소 6 개월 이상 보존적 치료에도 관절 구축의 호전을 보이지 않고, 주 관절 운동 시 기계적인 충돌을 보이고, 방사선학적 소 견상 척-상완 관절에 국한된 골극 형성소견이 있는 경 우 등 비교적 경도 및 중등도의 주관절 골관절염 환자 를 대상으로 하였으며, 주관절 전치환술이 필요한 진행 된 골관절염 환자와 척골 신경병증 증상이 있는 환자는
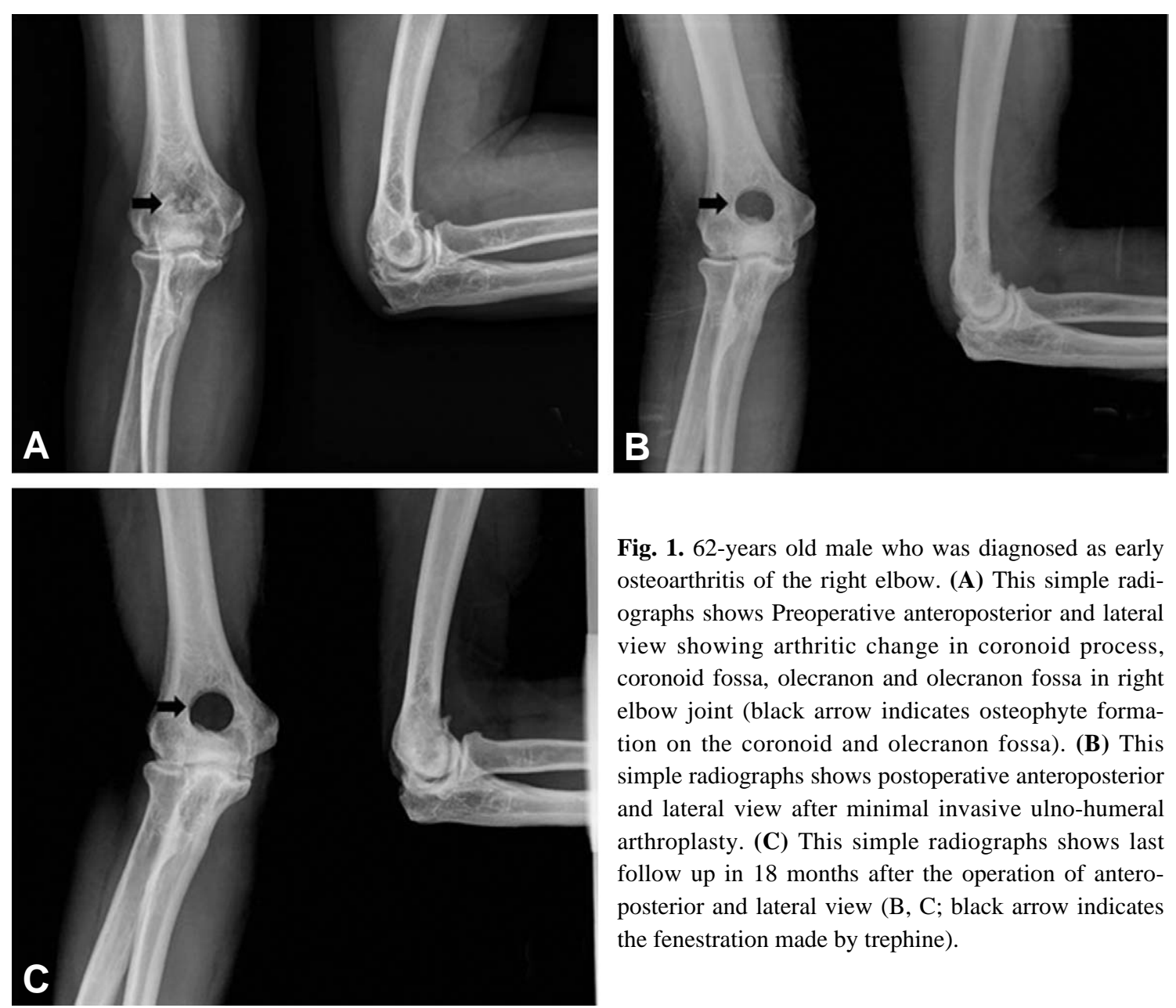

Fig. 1. 62-years old male who was diagnosed as early osteoarthritis of the right elbow. (A) This simple radiographs shows Preoperative anteroposterior and lateral view showing arthritic change in coronoid process, coronoid fossa, olecranon and olecranon fossa in right elbow joint (black arrow indicates osteophyte formation on the coronoid and olecranon fossa). (B) This simple radiographs shows postoperative anteroposterior and lateral view after minimal invasive ulno-humeral arthroplasty. (C) This simple radiographs shows last follow up in 18 months after the operation of anteroposterior and lateral view (B, C; black arrow indicates the fenestration made by trephine). 
본 연구에서 제외하였다 (Fig. 1). 증상 발현 후부터 수술까지 평균 시간은 2.9년 (0.5 10년)이었고 환자 의 평균 나이는 53세 (31 69세)였으며 남자 20예, 여 자 4예였다. 이들을 대상으로 평균 수술 시간, 술 전 및 술 후 관절 운동 범위, 술 후 관절 운동 시작까지의 시간, Mayo elbow performance score (MEPS)를 조사하였으며, 통계학적 검증은 대응 표본 $\mathrm{T}$ 검정법 (paired sample T test)을 이용하였다 $(p=0.000)$.

\section{수술 방법}

마취 하에 환자를 앙와위에서 지혈대를 착용시키고, 통상적인 방법으로 상지에 포타딘 용액을 이용한 소독 을 시행하고 견관절을 약 90 도 내전시키고, 주관절을 90 도 굴곡한 위치에서 상완골의 후방을 노출 시킨 상태 로 자세를 취하고 수술을 시작한다. 주두를 촉진하여 주두에서부터 근위부로 약 $4.5 \mathrm{~cm}$ 정도 종으로 피부 절개를 가하고 박리하여 삼두근을 노출시킨 후 삼두근 을 종으로 절개하고 양쪽 옆으로 젖힌다. 주두와의 시 야를 확보하고 절골기 (osteotome)를 이용하여 주변의 골극 및 돌출부를 제거한 뒤 관상톱 (trephine)으로 개
창 (trephination)을 하여 주두와 성형술을 시행한다. 이 창을 통하여 전방의 구상돌기의 골극을 제거하고 관 절 내 유리체도 제거한다. 주관절을 굴곡 및 신전하면 서 기계적으로 충돌하는 부분이 있는 지 확인하고, 충 돌 부분이 있으면 추가적인 골극 제거를 시행한다. 작 은 골 파편 또는 골질들이 관절 내에 남아 있지 않도록 충분히 세척한 후, 개창된 부위에 골 형성을 막기 위해 젤폼 (Spongostan ${ }^{\circledR}$, Johnson \& Johnson Medical, Korea)을 $1.5 \mathrm{~cm}$ 정도 너비로 길게 자른 후, 둥 글게 말아 개창된 주두와 안에 넣는다. 흡입 배액관을 삽입 후 삼두근, 피하를 흡수성 봉합사를 이용하여 봉 합하고 절개된 피부는 skin strip (Steri-Strip ${ }^{\mathrm{TM}}$, $3 \mathrm{M}$, Germany)으로 폐쇄한다 (Fig. 2).

$$
\text { 수술 후 처치 }
$$

수술 후 주관절을 완전히 신전시킨 상태에서 장상지 부목을 대놓고 수술 후 1 일째부터 부목을 제거하고 능 동적 및 수동적 관절운동을 시작하도록 권장하였고 운 동을 하지 않을 때나 밤에는 부목을 착용하여 신전 상 태를 유지하였다. 흡입되는 배액의 양이 하루 동안 10
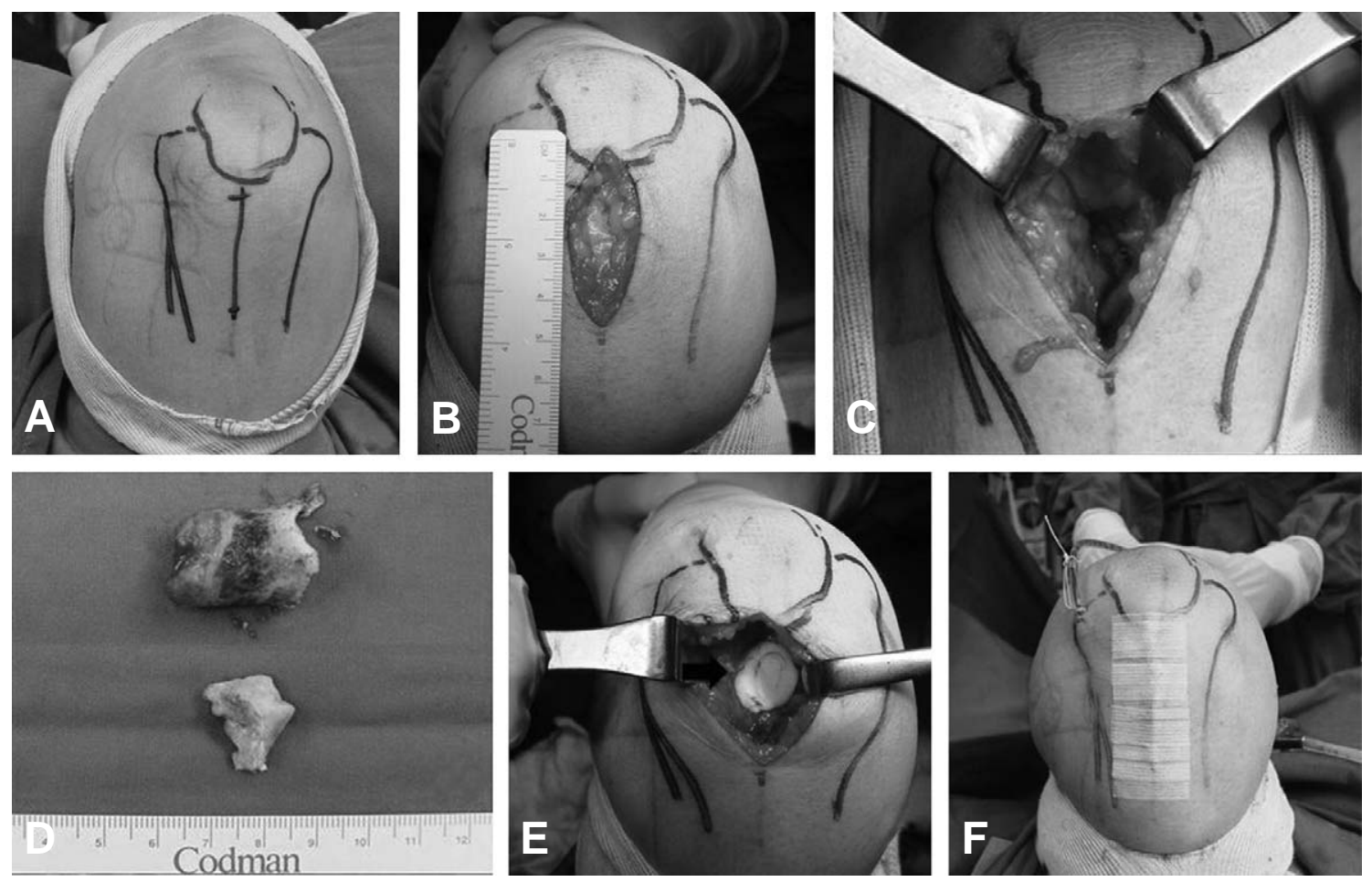

Fig. 2. The order of minimal invasive ulno-humeral arthroplasty in the patients with elbow arthritis in this study. (A) Draw the landmarks of the surface anatomy of elbow. (B) Make an about $4.5 \mathrm{~cm}$ midline longitudinal skin incision proximally from olecranon on distal posterior humerus area. (C) Expose the olecranon fossa. (D) This picture shows a trephinated bony fragment. (E) Insert the gelfoam in the olecranon fossa. (F) This picture shows wound after the operation (black arrow indicates the inserted gelfoam (Spongostan ${ }^{\circledR}$, Johnson \& Johnson Medical, Korea) after trephination). 
$\mathrm{cc}$ 이하로 감소하게 되면 배액관을 제거하였다.

\section{결 과}

입원 기간은 평균 7.6일 (7 14일)이었고 모든 환자 에서 신경 및 혈역학적 합병증은 없었으나 1 예에서 창 상 치유의 지연을 보였고, 7 예에서 운동 후 주관절 부 종이 발생하였으나 특별한 치료없이 호전되었다. 관절

Table 1. The clinical outcomes of Mayo Elbow Performance Score at 12 months after the operation in this study

\begin{tabular}{ll}
\hline \hline Function & Definition \\
\hline Pain & None 19 cases / Mild 5 cases \\
Range of motion (degree) & Average 119 \\
Instability & All cases stable \\
Joint function & 24 \\
MEPS & Excellent 19 cases / Good 5 cases \\
\hline
\end{tabular}

운동 범위는 술 전 평균 $25 \sim 104$ 도 (신전 $0 \sim 70$ 도, 굴 곡 80 130도)에서 술 후 1년 추시에서 평균 14 133 도 (신전 $0 \sim 45$ 도, 굴곡 $90 \sim 150$ 도)로 관절 운동 범위 가 평균 40 도 향상되었으며, 마취 시작부터 마취 종료 까지의 평균 수술 시간은 38 분 ( $25 \sim 55$ 분)이었다. $\mathrm{MEPS}$ 결과는 수술 후 경도의 통증 5 예, 관절 운동 범 위 점수는 평균 19.4점 (15 20점), 불안정성은 없었 고 관절 기능 점수는 평균 24점 (18 25점)으로 (Table 1), 우수가 19예, 양호가 5예였다 (Table 2).

흡입 배액관은 하루 동안의 배액양이 $10 \mathrm{cc}$ 이하로 감소하는 시점인 평균 3.3일 (3 7일)에 제거하였으나, 주관절 관절액 누출로 인해 배액양이 $10 \mathrm{cc}$ 이상 지속 되었던 3예에서는 7일까지 배액관을 유지 후 제거하였 다. 수술 후 합병증으로 창상 치유지연 1 예, 부종 7 예 가 발생하였으나 자연적으로 호전되었다 (Table 2).

Table 2. The data and clinical outcomes of patients with elbow arthritis treated by minimal invasive ulno-humeral arthroplasty in this study

\begin{tabular}{|c|c|c|c|c|c|c|c|c|c|c|}
\hline $\begin{array}{c}\text { Case } \\
\text { Number }\end{array}$ & $\begin{array}{l}\text { Age } \\
\text { /Sex }\end{array}$ & $\begin{array}{c}\text { Operation } \\
\text { time (min) }\end{array}$ & $\begin{array}{l}\text { ROM exercise } \\
\text { start time (day) }\end{array}$ & $\begin{array}{l}\text { F/U period } \\
\text { (month) }\end{array}$ & $\begin{array}{c}\text { H-vac } \\
\text { removal } \\
\text { time (day) }\end{array}$ & $\begin{array}{c}\text { Preop arc } \\
\text { of ROM } \\
\text { (degree) }\end{array}$ & $\begin{array}{c}\text { Postop arc } \\
\text { of ROM } \\
\text { (degree) }\end{array}$ & $\begin{array}{c}\text { Arc of ROM at } \\
\text { postoperative } \\
12 \mathrm{~m} \text { (degree) }\end{array}$ & MEPS* & $\begin{array}{l}\text { Compli- } \\
\text { cations }\end{array}$ \\
\hline 1 & $36 / \mathrm{M}$ & 40 & 1 & 12 & 3 & 80 & 150 & 130 & Excellent & \\
\hline 2 & $49 / F$ & 45 & 2 & 24 & 3 & 100 & 120 & 120 & Excellent & \\
\hline 3 & $58 / \mathrm{F}$ & 30 & 1 & 18 & 3 & 50 & 140 & 120 & Excellent & $\mathrm{POE}^{\dagger}$ \\
\hline 4 & $51 / \mathrm{M}$ & 55 & 1 & 18 & 3 & 90 & 140 & 130 & Excellent & \\
\hline 5 & $53 / \mathrm{M}$ & 25 & 1 & 12 & 3 & 75 & 150 & 140 & Excellent & \\
\hline 6 & 59/M & 45 & 2 & 24 & 3 & 80 & 120 & 90 & Excellent & \\
\hline 7 & $53 / \mathrm{F}$ & 50 & 3 & 48 & 5 & 40 & 150 & 110 & Good & POE \\
\hline 8 & $53 / \mathrm{M}$ & 25 & 5 & 48 & 7 & 85 & 140 & 110 & Good & \\
\hline 9 & $43 / \mathrm{M}$ & 55 & 1 & 18 & 3 & 50 & 140 & 130 & Excellent & \\
\hline 10 & $56 / \mathrm{M}$ & 25 & 1 & 12 & 3 & 55 & 140 & 130 & Excellent & \\
\hline 11 & $53 / \mathrm{M}$ & 30 & 1 & 12 & 3 & 85 & 150 & 140 & Excellent & POE \\
\hline 12 & $43 / \mathrm{M}$ & 25 & 1 & 12 & 3 & 70 & 110 & 90 & Excellent & POE \\
\hline 13 & $56 / \mathrm{M}$ & 25 & 1 & 12 & 3 & 60 & 150 & 140 & Excellent & POE \\
\hline 14 & $45 / \mathrm{M}$ & 35 & 1 & 18 & 3 & 105 & 150 & 130 & Excellent & \\
\hline 15 & 49/M & 30 & 2 & 24 & 3 & 55 & 110 & 100 & Excellent & \\
\hline 16 & $51 / \mathrm{M}$ & 40 & 4 & 48 & 5 & 120 & 130 & 110 & Good & $\mathrm{DWH}^{\dagger}$ \\
\hline 17 & $52 / \mathrm{M}$ & 25 & 1 & 12 & 3 & 80 & 130 & 130 & Excellent & \\
\hline 18 & $57 / \mathrm{F}$ & 30 & 1 & 12 & 3 & 80 & 120 & 105 & Excellent & \\
\hline 19 & $62 / \mathrm{M}$ & 50 & 1 & 18 & 3 & 90 & 140 & 140 & Excellent & \\
\hline 20 & $65 / \mathrm{M}$ & 45 & 2 & 32 & 3 & 85 & 130 & 80 & Good & POE \\
\hline 21 & 47/M & 45 & 1 & 18 & 3 & 100 & 150 & 140 & Excellent & \\
\hline 22 & $51 / \mathrm{M}$ & 50 & 1 & 12 & 3 & 80 & 140 & 120 & Excellent & POE \\
\hline 23 & $57 / \mathrm{M}$ & 45 & 2 & 48 & 3 & 100 & 130 & 100 & Good & \\
\hline 24 & $50 / \mathrm{M}$ & 50 & 2 & 18 & 3 & 70 & 120 & 120 & Excellent & \\
\hline Average & 53 & 38 & 1.6 & 22 & 3.3 & 79 & 135 & 119 & & \\
\hline
\end{tabular}

*MEPS: Mayo Elbow Performance Score, ${ }^{\dagger} \mathrm{POE}$ : Postoperative edema, ${ }^{\dagger}$ DWH: Delayed wound healing. 


\section{고 찰}

주관절 골관절염의 수술적 치료 방법에는 변연 절제 관절 성형술 (debridement arthroplasty), ${ }^{6.7)}$ 관절경 적 변연 절제술, ${ }^{8}$ 삽입형 관절 성형술 (interpositional arthroplasty), ${ }^{9)}$ Outerbridge-Kahiwagi (OK) 술식, Morrey의 변형된 $\mathrm{OK}$ 술식, ${ }^{4.5)}$ 주관절 전치환술 등 다양한 수술 방법이 알려져있으나, 주관절 관절염의 정도에 따른 적응증은 논쟁 중이다. 저자들은 경도 및 중등도 주관절 관절염 환자들에서 최소 침습적 척골 상 완 관절 성형술에 대한 연구를 시행하여, 관절 운동 범 위는 술 전 평균 25 104도에서 1년 추시 후 평균 14 133도로 평균 40도 향상되었으며, MEPS 결과는 우수가 19 예, 양호가 5 예의 결과를 얻어, 이 술식의 임 상적 유용성을 확인하였다.

주관절은 상완-척골과 상완-요골 관절로 구성되어 있 고 굴곡과 신전을 허용하는 경첩 관절으로서, Morey 등은 주관절의 정상 운동 범위 정도를 $0 \sim 146$ 도로 보고 하였다. ${ }^{10)}$ 주관절의 퇴행성 변화는 주관절 굴곡 구축의 주요 원인이며 동통과 기능 장애를 일으켜 일상 생활의 제한을 가져온다. 주관절 골관절염에 있어 굴곡 구축의 원인은 외상성 관절 구축에서와 같이 관절낭의 만성 염 증 반응 이후의 섬유화 구축뿐 아니라. 관절의 불일치 성, 이소성 골화증, 화상, 유리체, 이두근과 삼두근의 유착 등이 그 원인인데, 골극과 유리체 등으로 인하여 상완 척골 관절에서 기계적인 충돌이 일어나는 경우에 는 동통뿐 아니라 관절 운동의 제한을 일으키게 한다. ${ }^{11}$ 대부분 주관절의 초기 골관절염 치료는 보존적 치료를 시행하는 것이지만, 보존적 치료에도 호전이 없고, 주 관절 골극 형성이 광범위하고, 주관절 운동 범위의 제 한이 크고, 척골 신경병증 또는 충돌 증후군이 동반된 경우 수술적 치료를 고려하게 된다.

주관절 퇴행성 관절염에 대한 방사선적 기초 연구에 서 Kato 등 ${ }^{12)}$ 은 관절염 변화의 호발 장소는 구상돌기와 주두라고 보고한 바 있다. 한편 구상돌기와 주두의 내 측 변연에 골극이 생기면 운동 범위 제한의 원인이 되 는데 이는 척골 활차 절흔의 곡률 반경이 감소되어 주 관절 운동 범위의 제한이 발생하는 것으로 알려져 있 다. ${ }^{13)}$

주관절의 퇴행성 관절염 환자에서 침습적 관절 성형술 인 Kashiwagi의 OK 술식은 상완-척골 관절과 주두와 의 골극 제거 및 유리체 제거를 위하여 주두보다 근위부 의 상완부 원위부 후방에서 시작하는 $10 \mathrm{~cm}$ 의 종절개를 가한 후, 삼두근의 근섬유 방향과 평행하게 가르고 (triceps splitting) 주두와에 접근한다. 이 술식은 안전하 고 간단하며 합병증이 적다고 알려져 있다. ${ }^{5.12 .14)}$ 반면에 Morrey의 '변형된 OK 술식' 은 전통적인 $\mathrm{OK}$ 술식과
달리 관상톱을 사용하고, 항상 척골 신경을 노출하여 그 부위에서 삼두근을 젖혀서 (triceps elevation) 접근한 다. ${ }^{15)}$ 저자들은 본 연구에서 이 두 가지 술식의 장점을 이용하고 피부 절개를 최소화한 최소 침습적 척골 상완 관절 성형술을 사용하였는데, 저자들이 사용한 방법은 ‘변형된 $\mathrm{OK}$ 술식' 처럼 관상톱을 사용하고, 전통적인 $\mathrm{OK}$ 술식과 같이 삼두근을 가르고 접근하지만, 피부 절 개를 주두단보다 근위부로 제한하므로 $4.5 \mathrm{~cm}$ 정도의 작은 절개가 가능하고 이로 인한 통증 감소와 빠른 재 활이 가능하다는 차이가 있다.

최근에는 관절경 기술이 발달함에 따라 관절경을 이 용하여 주관절 관절염을 수술하는 보고가 증가하고 있 다. 그러나 관절경 술식 자체가 술자의 숙련된 기술을 요하며 신경 혈액학적 손상의 가능성이 있으며 수술의 적응증이 경도의 관절 구축에만 제한된다는 한계가 있 으며, ${ }^{16)}$ 수술 준비 시간이 길다는 단점이 있다.

이러한 여러 수술적 방법 중 경도 및 중등도의 주관 절 관절염을 지닌 환자에서 척골-상완 관절 성형술을 시행함에 있어서 본 연구에서는 최소 침습적 방법을 사 용하였는데 저자들은 이 방법이 수술 시간이 짧고, 술 후 환자의 통증이 적고, 조기 관절 운동이 가능하다는 점에서 선택할 만한 수술이라고 사료된다. 그러나 본 술식은 척골 신경으로의 접근이 불가하므로 척골신경병 증이 있는 환자에서 사용이 어렵고, 구축이 심하여 예 방적 척골 신경 감압술이 필요한 주관절염 환자에서는 시행하기 어렵다는 단점이 있다. 또한 본 연구에서는 수술 후 굴곡 운동 범위의 호전이 비교적 양호하였지만 주관절 내측 측부 인대의 후방 섬유로의 접근에 제한이 있어, 굴곡 제한이 심한 신전 구축 환자에서는 본 술식 의 적용에 한계가 있을 것으로 사료된다.

본 연구의 제한점으로는 비교적 증례의 수가 적고, 다른 술식과의 비교 연구가 아니며, 장기 추시 결과가 아니라는 점, 후향적 연구인 점을 들 수 있으며, 향후 장기 추시 연구를 비롯한 지속적인 연구가 필요할 것으 로 사료된다.

\section{결 론}

최소 침습적 척골 상완 관절 성형술은 최소의 후방절 개를 사용하므로 수술 시간이 짧고, 술 후 통증이 적으 며, 조기 관절 운동이 가능하다는 측면에서 전통적인 $\mathrm{OK}$ 술식 및 Morrey의 변형된 술식보다 유리하며, 제 거가 어려운 구상돌기와 주두에서의 골극 제거가 용이 하고, 수술 시간이 짧다는 측면에서 관절경적 수술보다 유리한 장점이 있어, 초기 및 중등도 주관절 관절염 환 자의 치료에서 선택 가능한 수술 방법이라 사료된다. 


\section{REFERENCES}

1. Cheon SJ, Lee DH, Cha SH, Kim HT, Suh JT. Debridement arthroplasty posteromedial approach in elbow joint with pain and bony limitation of motion. $J$ Korean Shoulder Elbow Soc. 2009;12:67-75.

2. Tashjian RZ, Wolf JM, Ritter M, Weiss AP, Green A. Functional outcomes and general health status after ulnohumeral arthroplasty for primary degenerative arthritis of the elbow. J Shoulder Elbow Surg. 2006; 15:357-66.

3. Forster MC, Clark DI, Lunn PG. Elbow osteoarthritis: Prognostic indicators in ulnohumeral debridement--the Outerbridge-Kashiwagi procedure. J Shoulder Elbow Surg. 2001;10:557-60.

4. Lee YG, Kim HS, Jeon YS, Jo YR. Debridement Arthroplasty for Post-Traumatic Stiff Elbow. J Korean Shoulder Elbow Soc. 1998;5:242-9.

5. Morrey BF. Primary degenerative arthritis of the elbow. Treatment by ulnohumeral arthroplasty. J Bone Joint Surg Br. 1992;74:409-13.

6. Oka Y. Debridement arthroplasty for osteoarthrosis of the elbow. Acta Orthop Scand. 2000;71:185-90.

7. Cheon SJ, Lee DH, Cha SH, Kim HT, Suh JT. Debridement Arthroplasty using Posteromedial Approach in Elbow Joint with Pain and Bony Limitation of Motion. J Korean Shoulder Elbow Soc. 2009; 12:67-75.

8. Chun CH, Kim JW, Lim JC. Results of Arthroscopic Debridement of the Elbow Osteoarthritis. J Korean
Shoulder Elbow Soc. 2009;12:53-60.

9. Wright PE, Froimson AK, Stewart MJ. Interpositional arthroplasty of the elbow. The Elbow and Its Disorders. 2nd ed. Philadelpha: Saunders; 1993. 61122.

10. Morrey BF, Askew LJ, Chao EY. A biomechanical study of normal function elbow motion. J Bone Joint Surg Am. 1981;63:872-7.

11. Viola RW, Hastings H 2nd. Treatment of ectopic ossification about the elbow. Clin Orthop Relat Res. 2000; 370:65-86.

12. Kato H, Hirayama T, Minami A, Iwasaki N, Hirachi K. Cubital tunnel syndrome associated with medial elbow Ganglia and osteoarthritis of the elbow. J Bone Joint Surg Am. 2002;84:1413-9.

13. Miyano S. A study of pattern on progression of elbow osteoarthritis. J Hokkaido Orthopaedic Traumatology. 1987;31:19-28.

14. Antuña SA, Morrey BF, Adams RA, O'Driscoll SW. Ulnohumeral arthroplasty for primary degenerative arthritis of the elbow: long-term outcome and complications. J Bone Joint Surg Am. 2002;84:2168-73.

15. Minami M, Kato S, Kashiwagi D. OuterbridgeKashiwagi's method for arthroplasty of osteoarthritis of the elbow 44 elbows followed for 8-16 years. J Orthop Sci. 1996;1:11-15.

16. Ball CM, Meunier M, Galatz LM, Calfee R, Yamaguchi K. Arthroscopic treatment of post-traumatic elbow contracture. J Shoulder Elbow Surg. 2002;11: 624-9. 


\section{초 록}

목적: 경도 및 중등도 주관절 관절염 환자에서 최소 침습적 척골-상완 관절 성형술의 임상적 유용 성에 대하여 알아보고자 한다.

대상 및 방법: 2000년 1월에서 2008년 12월까지 척골 신경 증상이 없는 경도 및 중등도의 주관절 관절염 환자에서 최소 침습적 척골-상완 관절 성형술을 시행받은 환자 29 예 중 1 년 이상 추시가 가능하였던 24예를 대상으로 하였다. 남자 20예, 여자 4예였으며, 평균 연령은 53세 (31 69세) 였고, 평균 수술 시간, 관절 운동 범위, 술 후 관절 운동 시작까지의 시간, 술 후 1 년 추시에서 Mayo elbow performance score (MEPS)를 조사하였다.

결과: 술 후 평균 1.8 일 (1 4일)째 수동적 및 능동적 관절 운동을 시작하였고, 평균 수술 시간은 38 분 ( $25 \sim 55$ 분)이었다. 관절 운동 범위는 술 전 평균 $25 \sim 104$ 도 (신전 $0 \sim 70$ 도, 굴곡 $80 \sim 130$ 도)에서 술 후 1 년 추시 상 평균 14 133도 (신전 0 45도, 굴곡 90 150도)로 평균 40도 관절 운동 범위가 향상되었으며, 술 후 관절 운동 시작까지의 시간은 평균 1.6 일 (1 5일)이었다. 술 후 1 년 추시에서 MEPS는 우수 19예, 양호 5 예이었다. 술 후 합병증으로 창상 치유지연 1 예, 술 후 부종 7 예가 있었으나 자연적으로 호전되었다.

결론: 경도 및 중등도 주관절 관절염 환자에서 최소 침습적 척골-상완 관절 성형술은 수술 시간이 짧고 조기 관절 운동이 가능하며 통증이 적으므로 임상적으로 유용한 수술이다.

색인 단어: 주관절, 관절염, 최소 침습적 척골 상완 관절 성형술 